\title{
DETECTION OF ORGANIC-RICH OIL SHALES OF THE GREEN RIVER FORMATION, UTAH, WITH GROUND-BASED IMAGING SPECTROSCOPY
}

\author{
Rebecca N. Greenberger ${ }^{1}$, Bethany L. Ehlmann ${ }^{1,2}$, Paul W. Jewell ${ }^{3}$, Lauren P. Birgenheier ${ }^{3}$, Robert O. \\ Green $^{1}$ \\ ${ }^{1}$ Jet Propulsion Laboratory, California Institute of Technology, 4800 Oak Grove Drive, Pasadena, CA \\ 91109, USA, Rebecca.N.Greenberger@jpl.nasa.gov \\ ${ }^{2}$ California Institute of Technology, Div. of Geological and Planetary Sci.,1200 E. California Blvd, \\ Pasadena, CA 91125, USA \\ ${ }^{3}$ University of Utah, Dept. of Geology and Geophysics, 115 S. 1460 East, Salt Lake City, UT 84112
}

\begin{abstract}
Oil shales contain abundant immature organic matter and are a potential unconventional petroleum resource. Prior studies have used visible/shortwave infrared imaging spectroscopy to map surface exposures of deposits from satellite and airborne platforms and image cores in the laboratory. Here, we work at an intermediate, outcrop-scale, testing the ability of field-based imaging spectroscopy to identify oil shale strata and characterize the depositional environments that led to enrichment of organic matter in sedimentary rocks within the Green River Formation, Utah, USA. The oil shale layers as well as carbonates, phyllosilicates, gypsum, hydrated silica, and ferric oxides are identified in discrete lithologic units and successfully mapped in the images, showing a transition from siliciclastic to carbonate- and organic-rich rocks consistent with previous stratigraphic studies conducted with geological fieldwork.
\end{abstract}

Index Terms - imaging spectroscopy, hyperspectral, oil shale, Green River Formation, sequence stratigraphy

\section{INTRODUCTION}

Oil shales form in unique depositional environments and contain thermally immature organics that can be processed to produce usable oil resources [1], [2]. The largest known deposit of oil shales is located in the Eocene-age Green River Formation of eastern Utah, Wyoming, and western Colorado [1]. In the portion of the Formation within the Uinta Basin, Utah, in-place resources are estimated to be 1.32 trillion barrels of oil [3].

The organics within oil shales have distinct visible/shortwave infrared (VSWIR) reflectance properties that allow them to be identified within matrices of mineral constituents in rocks and sediments [4], [5]. Imaging spectroscopy has been previously used to evaluate potential oil resources from airborne and satellite platforms [6]-[8] and in the laboratory [9], [10]. A newly emerging geologic technique is ground-based imaging spectroscopy, which permits rapid identification and mapping of compositional units at outcrop scale with a resolution of a few centimeters [11]. Here, we show the results of a study using imaging spectroscopy in the field to map sedimentary rock strata, including oil shales, of the Green River Formation near Vernal, Utah, USA. The goals of this work are to determine the utility of this technique to identify and map sedimentary rock lithologies, discriminate the presence and quality of oil shales, and understand the environmental conditions leading to formation of organic-rich strata.

\section{GEOLOGICAL SETTING}

The sedimentary rocks of the Green River Formation were deposited in tectonically-formed lakes during the middle Eocene [1], [2] and are at least 2100 feet thick [12]. Broadly, as lake level rose through time, siliciclastic input decreased, resulting in preservation of organic matter [2]. The most organic-rich portion of the Green River Formation in the Uinta basin, the Mahogany zone, formed at this time, and the organic matter present is largely algal in origin [13][15]. Two sedimentary sequences comprising portions of the Green River Formation were investigated. The first was an outcrop $\sim 150 \mathrm{~m}$ high known informally as the "Condo" section near Evacuation Creek located at $39^{\circ} 50.109^{\prime} \mathrm{N}$, $109^{\circ} 7.111^{\prime} \mathrm{W}$ [2]. This section contains alternations between siliciclastic-rich and carbonate- and oil shale-rich intervals and has been described in detail by [2], providing a geologic framework for interpretation of the imaging spectroscopy data. Visible at the top of the section are several darker layers of the Mahogany zone, which contains the richest oil shale beds in the basin. A Mahogany zone outcrop was investigated close-up at $39^{\circ} 50.76^{\prime} \mathrm{N}, 109^{\circ}$ 7.42' W. 


\section{METHODS}

Images were acquired with the California Institute of Technology imaging spectrometer system, built by Headwall Photonics, Inc. This system contains visible-near infrared (VNIR) and shortwave infrared (SWIR) sensors coboresighted on an optical bench for simultaneous acquisition of spectral imaging data spanning 0.4 to $2.6 \mu \mathrm{m}$. The VNIR sensor is a $2560 \times 2160$ pixel CMOS array, which samples wavelengths $0.4-1.0 \mu \mathrm{m}$ at $1.625 \mathrm{~nm}$ intervals with $5 \mathrm{~nm}$ spectral resolution. The SWIR sensor is a $640 \times 512$ pixel Stirling-cooled MCT focal plane array that covers wavelengths $0.97-2.60 \mu \mathrm{m}$ with $6 \mathrm{~nm}$ spectral resolution and spectral sampling. This pushbroom imaging spectrometer is mounted atop a tripod and a rotational stage to scan an outcrop line-by-line and create an image. The typical frame rates are $10-40 \mathrm{~ms}$, requiring $<5 \mathrm{~min}$. for a $180^{\circ}$ panorama.

After acquisition, images were calibrated to reflectance. First, a dark current measurement taken in the field was subtracted. Next, a flat field correction was performed using multiplicative factors derived from laboratory measurements of an integrating sphere. These corrections removed spectral and spatial non-uniformities. Corrections for atmospheric scattering and absorption and conversion to reflectance were performed either using the empirical line method [16], [17], derived from the averaged spectra of three Labsphere calibration targets in the scene (approximate reflectances of 99\%, 20\%, and 5\%) or using a dark object subtraction [18] and multiplicative correction using the 99\% calibration panel. Finally, observed offsets between the VNIR and SWIR detectors, which likely result from slight variations in detector response or errors in co-registration, were removed using a multiplicative factor, scaling SWIR reflectance at $969.3 \mathrm{~nm}$ to VNIR reflectance at $968.5 \mathrm{~nm}$.

Spectral parameters [19] were calculated to map absorption features that result from specific molecular vibrations or electronic transitions within mineral structures. Combinations of spectral parameters [20] were then used to map specific mineralogies. Vegetation was identified and masked using a linear unmixing algorithm, and shadows were masked where possible using band ratios to highlight artifacts in atmospheric absorption bands that generally were highest in the darkest shadows. A linear unmixing algorithm was attempted to map lithologies but could not distinguish fine shifts in the center wavelengths of spectral features indicative of different compositional units and was overwhelmed by differences in slope and iron oxide associations. Combinations of spectral parameters tuned to the features of interest proved most successful at distinguishing the lithologies present here. a)

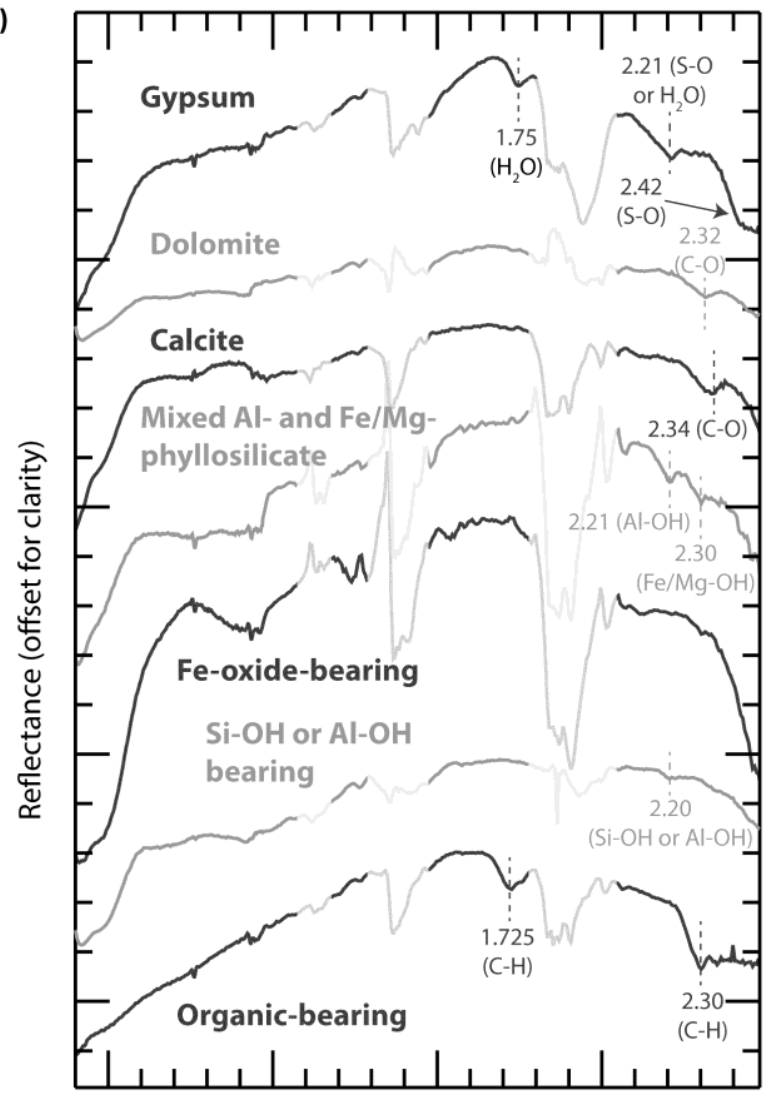

b)

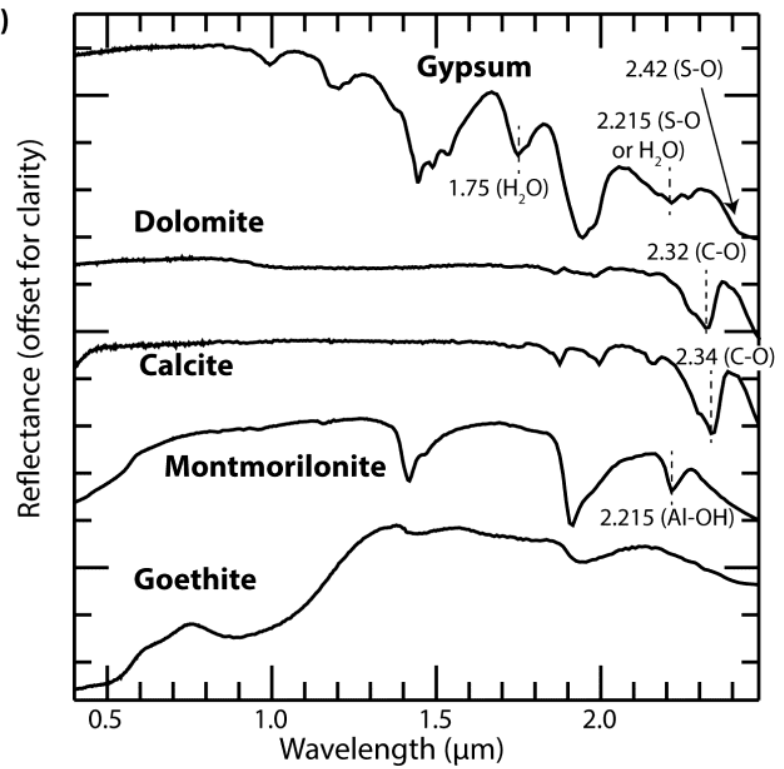

Figure 1. a) Reflectance spectra of some lithologies present at the investigated outcrops labeled with the spectral interpretation, band centers (in $\mu \mathrm{m}$ ), and band assignments. Zones of atmospheric absorption have been partially masked, and the VNIR portion of each spectrum was smoothed with a moving average. b) Library spectra from the USGS library [24]. Band assignments are from [5], [21], [23], [25]. 
a)

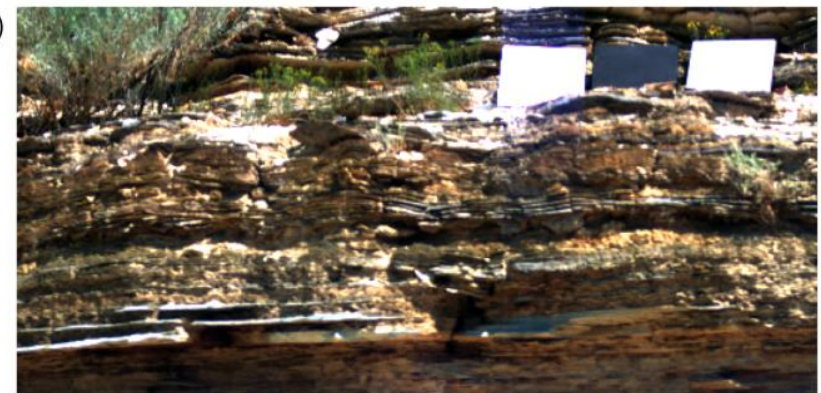

$50 \mathrm{~cm}$

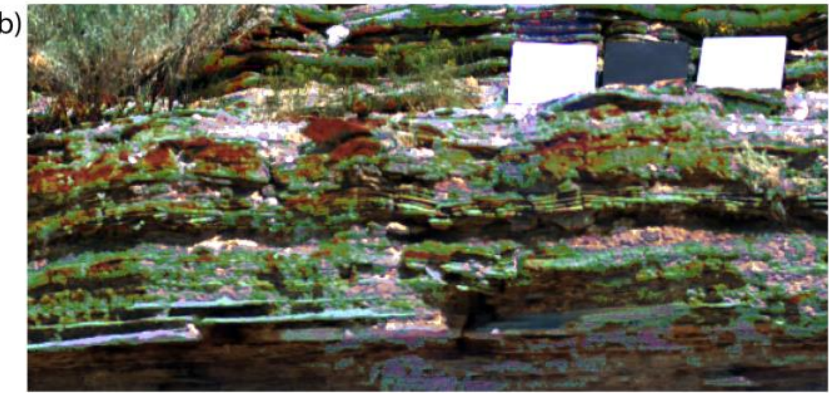

BD1725 organic proxy

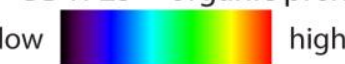

Figure 2. a) Approximate true color composite image of a portion of an image of the Mahogany formation. b) Approximate true color image with the strength of the $1.725 \mu \mathrm{m}$ absorption feature that indicates organic material overlain. Data are only shown where there were not strong indications of other minerals (e.g., gypsum). Vegetation, the darkest shadows, and the calibration targets have been masked in the BD1725 overlay.

a)

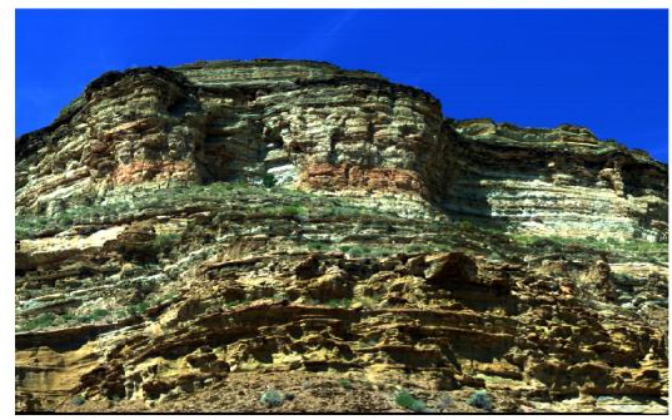

b)

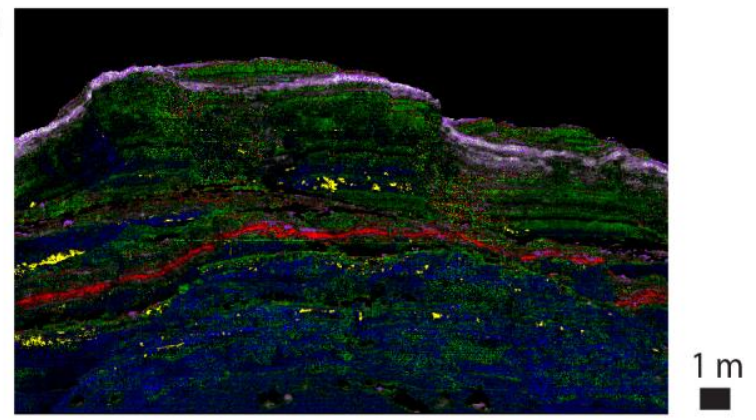

c)

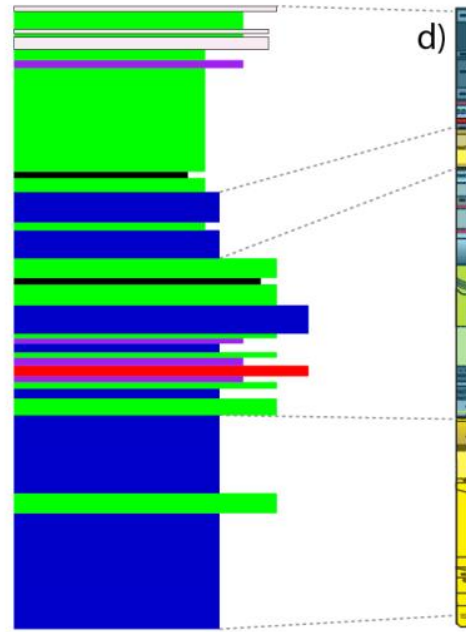
Legend (parts b and $c$ ):
$\mathrm{Si}-\mathrm{OH}$ or Al-OH bearing materials Dolomite
Calcite

d)

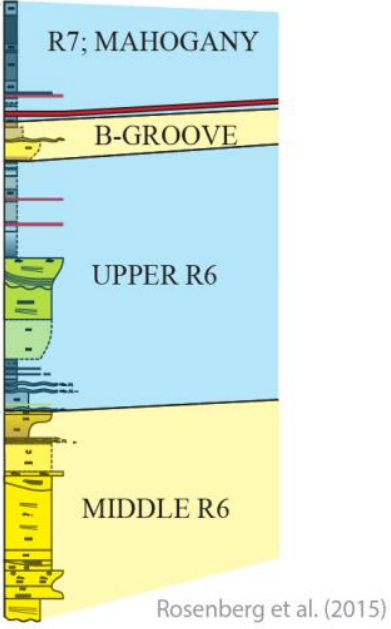

Gypsum

Organics (little carbonate)

Organics (more carbonate)

Unclassified, sky, or vegetation

Figure 3. a) Approximate true color composite image of Condo section sedimentary strata. The dark layers near the top are Mahogany Formation. b) Spectral parameter image with legend shown to the right. Vegetation has been masked. c) Stratigraphy of the outcrop inferred from imaging spectroscopy with colors corresponding to the legend and (b). Gypsum occurs in enriched lenses and/or weathering products. d) Stratigraphy from [2] created with traditional sedimentology field methods. Blue zones have higher organic content, and yellow zones have lower organic content. See [2] for additional information about colors and symbols. Dashed lines show approximate correlations between (c) and (d) strata.

\section{RESULTS}

The following lithologies were identified through spectroscopy (Fig. 1): gypsum, mixed $\mathrm{Fe} / \mathrm{Mg} / \mathrm{Al}$-bearing phyllosilicates including smectites and illite, $\mathrm{Fe}^{3+}$-oxides, calcite, dolomite, Si-OH bearing materials, and lithologies with high organic content (oil shales) (e.g., [21]-[23]). Mineral identifications through spectroscopy are consistent with the literature from prior geologic mapping [2] with the exception of gypsum, which was not identified previously and seems to occur as weathering products or in enriched lenses. The oil shales (bottom spectrum in Fig. 1a) have spectra characterized by an absorption feature at $1.725 \mu \mathrm{m}$ and a steep drop in reflectance followed by multiple absorption features at $2.30 \mu \mathrm{m}$. The relatively strong feature at $1.725 \mu \mathrm{m}$ has previously been attributed to overlapping C- 
$\mathrm{H}$ stretching overtones and combination tones [5]. The absorption features longward of $2.30 \mu \mathrm{m}$ are due to combinations of $\mathrm{C}-\mathrm{H}$ bending and stretching fundamentals [5]. Absorptions at $\sim 1.7 \mu \mathrm{m}$ and $\sim 2.3 \mu \mathrm{m}$ also occur in gypsum and carbonates or $\mathrm{Fe} / \mathrm{Mg}$ phyllosilicates, respectively; however, the spectral signature of organics can be separated by the co-occurrence of the features, the slightly different central position of the $1.725 \mu \mathrm{m}$ feature (vs. $1.75 \mu \mathrm{m}$ in gypsum), and a strongly downward sloping reflectance in VNIR wavelengths.

Most of the in situ rocks of the Mahogany zone have spectra dominated by absorption features due to organics (Fig. 2), though occasional layers or ledges of other phases, mostly carbonates (calcite and dolomite), gypsum, and mixed $\mathrm{Fe} / \mathrm{Mg} / \mathrm{Al}$-bearing clays, are present. Mapping the strength of the $1.725 \mu \mathrm{m} \mathrm{C}-\mathrm{H}$ absorption feature shows layers with higher inferred organic content (reds and yellows in Fig. 2b). Mapping the larger-scale Condo outcrop with its $>100 \mathrm{~m}$ of sedimentary rocks exposed in the section (Fig. 3), quartz- and silica-rich lithologies such as sandstone or aluminum phyllosilicate-rich mudstones generally dominate spectrally in the bottom portion of the outcrop whereas carbonate-rich units (limestone and dolostone) and organicrich oil shales characterize the upper portion.

\section{DISCUSSION}

These ground-based imaging spectroscopy analyses fill a gap in scale between orbital and laboratory imaging spectroscopy measurements of similar materials [6]-[10] and provide the advantage of mapping the types of vertical exposures commonly seen in field settings that are difficult or impossible to map from airborne platforms. The inferred stratigraphy from imaging spectroscopy here (Fig. 3c) compares well with the sequence stratigraphy work of [2] using traditional sedimentary and core analysis techniques (Fig. 3d) and adds additional data on the variation in mineralogy of the strata around the organic-rich zones. In addition, the depositional environments and changing environmental conditions that led to the preservation of abundant organic matter can be inferred from these data by analyses of the sequence stratigraphy of siliciclastic- and carbonate-rich facies associated with the oil shales. At a broad scale, there is a transition from spectra consistent with siliciclastic material likely fluvial in origin to carbonates and organics (lacustrine), while at higher resolution alternations between siliciclastic and carbonate layers are present. These results are consistent with interpretations by [2] of a deepening lake in the Uinta Basin lowering siliciclastic input and leading to the generation and preservation of carbonate and organic-rich rocks higher in the section.

\section{CONCLUSIONS}

Imaging spectroscopy of Green River Formation sedimentary rocks containing oil shale strata successfully identifies and maps organic-rich oil shales as well as carbonates, phyllosilicates, gypsum, and ferric oxide minerals and provides the ability to do sequence stratigraphy. Mapping locations of oil shales helps remotely identify this potential resource, and lithologic discrimination provides insights into the creation of these organic-rich shales. Collectively, the data indicate ground-based imaging spectroscopy is a powerful new tool for sedimentary sequence stratigraphy on Earth and other planets (e.g., Mars).

\section{ACKNOWLEDGMENTS}

We thank Jen Morris and Julia Howe for field assistance. RNG was supported by an appointment to the NASA Postdoctoral Program at the Jet Propulsion Laboratory, California Institute of Technology, administered by Universities Space Research Association under contract with NASA, and PJW and LPB were partially supported by a 2014-2015 grant from the Utah Geological Survey. A NASA Planetary Major Equipment grant (NNX13AG74G) and Rose Hills Foundation grant provided partial support to BLE for purchase of the imaging spectrometer system. (C) 2016. All rights reserved.

\section{REFERENCES}

[1] J. R. Dyni, Geology and resources of some world oil-shale deposits. US Dept. of the Interior, USGS Scientific Investigations Report 2005-5294, 2006.

[2] M. J. Rosenberg, L. P. Birgenheier, and M. D. V. Berg, "Facies, Stratigraphic Architecture, and Lake Evolution of the Oil Shale Bearing Green River Formation, Eastern Uinta Basin, Utah," in Stratigraphy and Paleolimnology of the Green River Formation, Western USA, M. E. Smith and A. R. Carroll, Eds. Springer Netherlands, 2015, pp. 211-249.

[3] USGS Oil Shale Assessment Team, "Oil Shale resources of the Uinta Basin, Utah and Colorado," US Geol. Surv. Digit. Data Ser. DDS-69-BB 7 Chapters, 2010.

[4] E. A. Cloutis, M. J. Gaffey, and T. F. Moslow, "Characterization of minerals in oil sands by reflectance spectroscopy," Fuel, vol. 74, no. 6, pp. 874-879, Jun. 1995.

[5] E. A. Cloutis, "Spectral Reflectance Properties of Hydrocarbons: Remote-Sensing Implications," Science, vol. 245, no. 4914, pp. 165-168, Jul. 1989.

[6] B. Hörig, F. Kühn, F. Oschütz, and F. Lehmann, "HyMap 
hyperspectral remote sensing to detect hydrocarbons," Int. J. Remote Sens., vol. 22, no. 8, pp. 1413-1422, May 2001.

[7] F. Kühn, K. Oppermann, and B. Hörig, "Hydrocarbon Index an algorithm for hyperspectral detection of hydrocarbons," Int. J. Remote Sens., vol. 25, no. 12, pp. 2467-2473, Jun. 2004.

[8] D. Xu, G. Ni, T. Jiang, L. Jiang, and M. Chi, "Integration of field work and hyperspectral data for oil and gas exploration," in Geoscience and Remote Sensing Symposium, 2007. IGARSS 2007. IEEE International, 2007, pp. 3194-3197.

[9] M. Speta, B. Rivard, J. Feng, M. Lipsett, and M. Gingras, "Hyperspectral imaging for the determination of bitumen content in Athabasca oil sands core samples," AAPG Bull., vol. 99, no. 7, pp. 1245-1259, Jul. 2015.

[10] M. Speta, B. Rivard, J. Feng, M. Lipsett, and M. Gingras, "Hyperspectral imaging for the characterization of athabasca oil sands drill core," in Geoscience and Remote Sensing Symposium (IGARSS), 2013 IEEE International, 2013, pp. 2184-2187.

[11] R. N. Greenberger, J. F. Mustard, B. L. Ehlmann, D. L. Blaney, E. A. Cloutis, J. H. Wilson, R. O. Green, and A. A. Fraeman, "Imaging spectroscopy of geological samples and outcrops: Novel insights from microns to meters," GSA Today, vol. 25, no. 12, pp. 4-10, 2015.

[12] W. B. Cashion, "Geology and Fuel Resources of the Green River Formation, Southeastern Uinta Basin, Utah and Colorado," USGS Prof. Pap., vol. 548, Jan. 1967.

[13] J. R. Dyni, "Oil-shale resources of the Mahogany Zone in eastern Uinta Basin, Uintah County, Utah," U.S. Geological Survey, USGS Numbered Series 91-285, 1991.

[14] M. D. Vanden Berg, "Basin-wide evaluation of the Uppermost Green River Formation's Oil-Shale Resource, Uinta Basin, Utah and Colorado," Utah Geological Survey Special Study 128, 2008.

[15] L. P. Birgenheier and M. D. Vanden Berg, "Core-based Integrated Sedimentologic, Stratigraphic, and Geochemical Analysis of the Oil Shale Bearing Green River Formation, Uinta Basin, Utah," US DOE, Oil \& Natural Gas Technology Topical Report, Apr. 2011.

[16] R. J. Aspinall, W. A. Marcus, and J. W. Boardman, "Considerations in collecting, processing, and analysing high spatial resolution hyperspectral data for environmental investigations," J. Geogr. Syst., vol. 4, no. 1, pp. 15-29, Mar. 2002.

[17] J. E. Conel, R. O. Green, G. Vane, C. J. Bruegge, R. E. Alley, and B. J. Curtiss, "AIS-2 radiometry and a comparison of methods for the recovery of ground reflectance," 1987.

[18] P. S. Chavez, "An improved dark-object subtraction technique for atmospheric scattering correction of multispectral data," Remote Sens. Environ., vol. 24, no. 3, pp. 459-479, Apr. 1988.

[19] R. N. Clark and T. L. Roush, "Reflectance Spectroscopy: Quantitative Analysis Techniques for Remote Sensing Applications," J. Geophys. Res., vol. 89, no. B7, p. PP. 63296340,1984

[20] R. N. Greenberger, J. F. Mustard, E. A. Cloutis, P. Mann, J. H. Wilson, R. L. Flemming, K. M. Robertson, M. R. Salvatore, and C. S. Edwards, "Hydrothermal alteration and diagenesis of terrestrial lacustrine pillow basalts: coordination of hyperspectral imaging with laboratory measurements," Geochim. Cosmochim. Acta, vol. 171, pp. 174-200, 2015.

[21] G. R. Hunt and J. W. Salisbury, "Visible and near infrared spectra of minerals and rocks. II. Carbonates," Mod. Geol., vol. 2, pp. 23-30, 1971.

[22] G. R. Hunt and R. P. Ashley, "Spectra of altered rocks in the visible and near infrared," Econ. Geol., vol. 74, no. 7, pp. 16131629, Nov. 1979.

[23] R. N. Clark, T. V. V. King, M. Klejwa, G. A. Swayze, and N. Vergo, "High Spectral Resolution Reflectance Spectroscopy of Minerals," J. Geophys. Res., vol. 95, no. B8, pp. 12653-12680, 1990.

[24] R. N. Clark, G. A. Swayze, R. Wise, E. Livo, T. Hoefen, R. Kokaly, and S. J. Sutley, "USGS digital spectral library splib06a: US Geological Survey, data series 231. 2007.

[25] E. A. Cloutis, F. C. Hawthorne, S. A. Mertzman, K. Krenn, M. A. Craig, D. Marcino, M. Methot, J. Strong, J. F. Mustard, D. L. Blaney, J. F. Bell III, and F. Vilas, "Detection and discrimination of sulfate minerals using reflectance spectroscopy," Icarus, vol. 184, no. 1, pp. 121-157, Sep. 2006. 